\title{
From transgression to pragmatism in reproductive medicine ${ }^{1}$
}

\author{
Claude SUREAU*
}

4 Boulevard du Château, 92200 Neuilly-sur-Seine, France

\begin{abstract}
It is difficult to harmonise faith and the desire to follow religious teachings and obligations on the one hand, and scientific advances and their use for the benefit of suffering humanity on the other. This is an especially delicate matter for patients and health professionals in reproductive medicine. It deals with the conflicting issues of contraception, termination of pregnancy, assisted reproduction, cloning, stem cells and embryo research. Beyond the technical aspects of these matters, the theoretical, legal, philosophical and religious implications must be explored, including the concepts of personality, individuality, human dignity, autonomy, beneficence and justice. Most importantly, an analysis must be made of the beginnings of a human being, the protection it deserves, the concept and time of ensoulment, the need for pragmatism and the right of transgression (hence the title of this article).
\end{abstract}

contraception / termination of pregnancy / assisted reproduction / cloning / stem cells / embryo research / personality / individuality / human dignity / autonomy / beneficence / justice / pragmatism / transgression

\section{INTRODUCTION}

The past few days, dedicated to the memory of Charles Thibault, have highlighted his exceptional contribution to our knowledge of animal reproduction and to its application by clinicians to human procreation, particularly in vitro fertilisation.

I would like to speak on an aspect of his work which I believe was truly significant. It is an aspect that often involves complex relations, either uniting or separating "revealed truths" and scientific observations.
Charles Thibault was Catholic, like me. He believed in God, in One God, and in eternal life for the soul. A discreet allusion to his faith has already been made during this symposium by Philippe Chemineau, who spoke of his "presence above", of which I, too, am convinced.

In most areas of medicine, whether it be human medicine or the application of animal research in human medicine, conflict is unlikely to arise between philosophical or religious convictions, observational data and the attention paid to social crises and human suffering.

\footnotetext{
* Corresponding author: aleroux@ theramex.mc

${ }^{1}$ Please note that there was a lapse of several months between the oral presentation of this article and the written document. During this period, several, mainly legal, changes have occurred. They will be referred to in this article but should not be considered chronological inconsistencies.
} 
The same is not true for the decision to procreate, which involves the future of the unborn child, or not to procreate. I am tempted to think that there is no other discipline where Paul Ricoeur's phrase "Justice is neither what is legal nor what is good; rather, it is the result of their incessant dialectics" so aptly applies. Of course, uncertainty, fear and sometimes anxiety are not experienced by believers alone, but are shared by many agnostics. Believers and "unbelievers" alike often come together to extol universal, eternal values, or those that should be, such as human dignity, autonomy, beneficence and justice, as underlined in the Belmont Report over twenty years ago.

The real problem for believers, however, is a reference to concepts that are not "dogmatic" per se, since they are not related to "dogma", but rather to moral values and the "constant teaching of the Magisterium". The believers' struggle with procreation remains despite the fact that, over the centuries, this teaching has undergone significant, opportune changes, which create new issues and questions for the future. In the meantime, and this was particularly true for Charles Thibault, these developments lead us to consider whether or not they are legitimate. They compel us to reflect on our duty to contribute to the changes and to weigh the consequences of following norms to the letter, norms that are perhaps destined to become archaic. And all this, while human beings continue to suffer. This is the eternal dilemma of choosing between the spiritual and the temporal, the eternal and, some say, damnable temptation of pragmatism, even transgression, hence the title of this presentation. The most striking example of this struggle is without doubt the firm, often repeated assertion that human life begins at conception, with the consequences including pregnancy termination and assisted reproduction, together with "non-natural" contraception, often considered to be immoral.
With, on the one hand, the transcendent character of truths and obligations, and on the other, the observation of tragedies which as humans we cannot ignore and issues arising from scientific progress, "our conscience is never at peace", as Suzanne Rameix once put it ${ }^{2}$.

We will now explore the matters that trouble our conscience, including conception and contraception, pregnancy termination, in vitro fertilisation, the use of human cell lines for research and treatment, and finally, human embryo research.

\section{CONCEPTION AND CONTRACEPTION}

Charles Thibault, as you know, participated in the work of the commission which studied the sensitive issue of fertility control at the Vatican. He shared his thoughts with me, which were in fact, the thoughts of the majority within the commission, but which unfortunately were not reflected in the Encyclical Humanae Vitae. For Charles Thibault, progress in paediatrics led naturally to the disappearance of "natural" regulation of demographics, that is, neonatal and infant mortality. It was therefore necessary to find other ways to control population numbers. He believed that, from a religious point of view, motivation was a more important consideration than technique. We saw no difference, neither he nor I, between using a mechanical means of contraception, using a biochemical means of contraception, and pinpointing a woman's infertile periods in order to "seize the opportunity". In other words, the thermometer seemed no more "artificial" than the Pill and we felt that to say the contrary would be to prefer the "letter" to the "Spirit". As regards abstinence, it is an entirely personal choice, often a highly moral one, as a

\footnotetext{
2 Rameix S. Between doing good and doing our duty, our conscience is never at peace, in: Fondements philosophiques de l'éthique médicale, Ellipses, 1996.
} 
number of believers from different confessions have shown; and should not be imposed in application of a political-religious policy, of which we also have many regrettable examples. Reproductive behaviour is above all the expression of individual autonomy, to be adjusted by taking into account the interest of the children.

The same reasoning led us to deplore the extremely conservative attitude of the courts, including the Cour de Cassation ${ }^{3}$, which refused to consider sterilisation for contraceptive reasons as anything but illicit because it was "a lifestyle choice". It was not until $1999^{4}$ that Article 16-3 of the French Civil Code was amended and the term "medical" replaced the term "therapeutic," and not until $2001^{5}$ that sterilisation came to be considered as a specific method of contraception. Was this simply a pragmatic attitude or was it an intolerable transgression of a taboo?

As far as contraception is concerned, there is no doubt that one of the major advances of the 20th century, in terms of technology and concept, was hormonal contraception. Yet it sparked vicious debate, both before and after the Neuwirth $\mathrm{Act}^{6}$ was passed. At the time, outrageous claims were made about how this liberty granted to women, who were obviously incapable of using it appropriately, would wreak havoc throughout society and families. Today, it is considered good form to criticise the attitude of certain communities toward women, but we forget that until recently French women were considered incapable or as minors, socially, politically and legally. We owe our gratitude to Lucien Neuwirth and those who supported him in his battle for this fundamental step in the emancipation of women. Again I ask, is this pragmatism or already transgression?

\footnotetext{
3 Translator's note: The highest court of appeal in France.

4 Article 70. Act 99-641 of 27.07.99.

5 Article 26 et seq. Act 2001-588 of 04.07.01.

6 28.12.67.
}

Hormonal contraception was also a fundamental step in changing the relationship between patients, women patients in this case, and medical practitioners. Until then, patients went to the doctor to be treated for a disease, to relieve their pain, if possible, and in any case, for a reassuring listening ear. Though often criticised, sometimes justifiably so, patients generally received assistance. There were some who found this relationship unbalanced or "asymmetrical" and abuse of medical power was occasionally denounced. Patients' rights were gradually recognised, achieving their fullest expression in the Kouchner Act of 4 March $2002^{7}$.

The origin of this fundamental development is found in the revolution of 1967 . For the first time, patients no longer went to the doctor to be relieved of physical or psychological pain, but to resolve a social problem, to make a "lifestyle choice" using medicine to deliberately disturb a mechanism that had until then been strictly normal. With the Neuwirth Act, the scope of medicine changed - it now directly modified a physiological process for personal, no longer medical, reasons. For the first time, medicine was used to "tamper" with humans, no longer sick human beings, as had always been its natural purpose, but healthy humans. It is here that the seeds were sown for all future development in the patientphysician relationship, and, as far as we are concerned, all of those in reproductive medicine. Some people grasped this immediately and analysed the sociological, moral, philosophical and political implications and this explains the now-hard to believe violent reactions and criticism of the time.

At that same time, there emerged one concept in particular, which I alluded to earlier when speaking about sterilisation, that of "convenience" as opposed to "medical necessity". I stated that the opposition could hardly be applied to sterilisation and even

\footnotetext{
${ }^{7}$ Act $2002-303$ of 04.03 .02 relative to patients' rights and the quality of the healthcare system.
} 
less so to contraception. Would anyone dare recall that the argument of "illegitimate convenience" was used to object to the reimbursement of obstetric analgesia by the public health care system until a decree was issued by Ms Veil in 1994? The same argument can be made for pregnancy termination, regardless of the reason, and assisted reproduction.

\section{PREGNANCY TERMINATION}

While Catholic practitioners and researchers, and most patients, in fact, have no hesitation in saying that contraception is legitimate, the same is not true for pregnancy termination. However, a number of distinctions must be made here, as the term "pregnancy termination" can refer to many different situations: we will specifically look at ectopic pregnancies, pregnancy termination where the mother's health is in danger, termination for foetal anomaly, whether proven or suspected, termination where the woman's condition causes her distress, and lastly, the terribly ambiguous issue of "contragestion".

\subsection{Ectopic pregnancy}

Ectopic pregnancy, specific to the human species, poses an obvious threat to the life of the mother, which, today, automatically justifies the destruction of the embryo - this is what some call "legitimate defence". This assertion is worthy of more in-depth analysis.

First of all, this was not always the case. From the beginning of the 20th century to the 1960s, eminent theologians insisted that it was "morally wrong" to wilfully destroy a living embryo, which should be protected even to the detriment of the mother. When people realised how inhuman this attitude was, they instead focused on the unavoidability (an arguable point, actually) of the embryo's death to justify the operation. Thus, the certain imminent death of a human being makes legitimate his/her immediate destruction. We will be looking at other examples of this logic. But the question is already clear: is this a matter of pragmatism or of transgression?

Technical progress has led to procedures whereby a small slit is made in the woman's fallopian tube to remove and destroy the embryo, or whereby the same embryo destruction is achieved through drugs alone. The purpose is, in any case, to leave intact the mother's reproductive organs to allow for future pregnancy. Thus, a choice between the life of the mother and the life of the child has turned into the deliberate destruction of a living embryo with future procreation in mind. This is a major evolution of concepts, which I am emphasising because it is a model for similar situations in reproductive medicine, to be analysed at a later point.

\subsection{Termination of a normal intrauterine pregnancy but where the mother's health is in danger}

This situation is comparable to an ectopic pregnancy. Medical advances, so often disparaged, have fortunately made this type of pregnancy termination rare, especially since the pathologies potentially responsible for it are usually detected before pregnancy, and can therefore be resolved with the use of effective contraception methods. This just goes to show, technical progress sometimes helps resolve moral dilemmas.

\subsection{Termination of pregnancy for foetal anomaly}

This is the opposite situation. Clearly, with continued progress in screening for congenital abnormalities (blood tests, ultrasound, etc.), researchers and practitioners, and parents above all, believers and nonbelievers alike, are faced with what I call tragic developments. This issue is farreaching, as it involves prenatal and preimplantation genetic diagnosis. Jacques 
Milliez $^{8}, \mathrm{I}^{9}$ and many others have written articles and books on the subject; I will take this time to underline just a few major points:

- Is it better to be alive, albeit deformed, or dead? This was the burning issue throughout France during the Perruche ${ }^{10}$ case and the legal proceedings that immediately followed $^{11}$, as well as later changes in legislation, together with a series of consequences including damages, insurance benefits and finally medical demographics. Here, I will only consider the moral aspects of the decisions taken or to be taken.

- If the answer is "yes", it is acceptable, in the name of the absolute respect of life and integrity of "a human being from conception" (Article $16^{12}$ of the French Civil Code, a binding article of constitutional value), to cause the human being in question atrocious suffering (for instance, epidermolysis bullosa) and his/her parents the no less unbearable sight of his/her suffering, until his/her unavoidable death.

- If the answer is "no", we are clearly on a slippery slope which may lead us to one day accept anything and everything in the quest for the "perfect child". We could be tempted to think twice about terminating pregnancies for situations for which a cure exists, such as the hare lip; perfectly tolerable abnormalities, such as the Turner syndrome; abnormalities with unpredictable consequences, such as agenesis of the corpus callosum or toxoplasmosis; or those than are often dealt with admirably well, such as the accepted birth of a child with Down's Syndrome. It is clear where an

\footnotetext{
8 Milliez J. L'euthanasie du fœetus, médecine ou eugénisme ? Odile Jacob, Paris, 1998.

9 Sureau C. Fallait-il tuer l'enfant Foucault ? Stock, Paris, 2003.

${ }^{10}$ Decision by the plenary assembly of the Cour de Cassation of 17.11.2000.

${ }^{11}$ Act $2002-303$ of 04.03 .02 relative to patients' rights and the quality of the healthcare system.

12 "Art. 16. - The Law prohibits any threat to human dignity of the individual, whose primacy is ensured and guarantees the respect of every human being from the beginning of his/her life."
}

extensive medical application of the "precautionary principle" might lead us. Eugenics is making a comeback, in prenatal diagnosis and perhaps even more obviously in preimplantation genetic diagnosis, as stressed by Jacques Testart. It is noteworthy that H. Gaymard, then French Secretary of State for Health, after hearing his colleague J.F. Mattei sum up the situation, and both of them perfectly aware of the potential consequences of any deviation, on two occasions ${ }^{13}$ agreed to grant the French Academy of Medicine its request that Down's Syndrome screening (via markers) and amniocentesis for high-risk cases be reimbursed by the public health care system. Is this now a question of pragmatism or transgression?

- Nonetheless, it is clearer with every passing day that their fears were founded and the abuses we apprehended can only continue due to the constant progress of medicine. For instance, with regards to the foetal karyotype, one day, a simple blood test, will replace amniocentesis, which is not always $100 \%$ risk-free. Medical practitioners are faced with an increasingly high demand to prevent malformations by prenatally destroying beings whose malformation is considered unacceptable or incompatible with a "happy life", according to our adult criteria. These same practitioners cannot but feel that they are the "refuse collectors" of a demanding society, which does not accept the abnormalities identified in some of its more fragile specimens, because it reflects back an unbearable image of itself, of a society which asks its doctors to remove the waste which it can no longer bear to look upon. What can we do, what can we suggest? Researchers and clinicians may have some thoughts to share, as long as our society is willing to accept pragmatism and sometimes transgression.

- There is one very telling case, telling in that it is paid no attention: that of anencephaly, or absence of the cranial vault and a

\footnotetext{
${ }^{13}$ Decree of 23.01.97, Decree of 11.02.99.
} 
large part of the brain, which inevitably causes death within minutes or hours of birth. This defect is increasingly being screened for during early pregnancy. Even the most ardent moralists accept the idea of pregnancy termination as soon as the diagnosis is known, (1) because knowing about the defect is psychologically unbearable for the mother, and that it is therefore absurd to permit for the natural course of the pregnancy, and (2) because the outcome is inevitable. A bold attitude for the moralists, indeed, since they are consenting to the destruction of a being, which they nevertheless consider to be a person from conception, due to its complete inability to survive on its own. Could this be considered a new "paradigm" to be applied to other situations, representing a practical decision which borders on transgression?

\subsection{Termination of pregnancy where the woman's condition causes her distress}

By now, thirty years on from the Veil $\mathrm{Act}^{14}$, everything has been said that could be said about a law that sparked such controversy and even hate. We remember the appalling comparisons made with crematoriums and the foetus in formaldehyde that was exposed at the rostrum of the Assemblée nationale. We perhaps remember less the preposterous case tried against Etienne Baulieu by Dr Nathanson before the 17th chamber of the Tribunal de Grande Instance $^{15}$. Originally a well-known, prosperous abortion doctor, Dr Nathanson later repented and went on to direct a film entitled The Silent Scream, which had some success. In the film, a horrified foetus is seen opening its mouth and screaming in terror upon "seeing" the cannula that is to destroy him. Baulieu was accused of defamation following his criticism of the film,

\footnotetext{
14 Act $75-17$ of 17.01 .75 .

15 Translator's note: A civil court for hearing complicated cases with three judges; the 17 th chamber hears press-related cases.
}

which, it must be said, very tendentiously combined images and interpretations. I was summoned as a witness for Baulieu and I have the sad memory of several leading medical experts who thought it wise, for "ideological" reasons, to lend their moral support to the film. Since then, of course, we have seen worse, not so much in France where the series of terminations performed are no longer paid much attention, but rather in the United States, where people still kill "in the name of life".

Charles Thibault and I were both well aware of what the Veil Act meant for women in terms of safety and protection of their life and health. I remembered those nights in the 1950s being on call at the Salpêtrière or another hospital and I also remember, week after week, the many complications after back-alley abortions, with their heavy consequences - death, after effects and suffering. I must say that I was, perhaps unlike Charles Thibault, more sensitive to the practical aspect of health protection, which also probably guided Ms Veil in her actions, than to the very "feminist" attitude adopted by a number of activists who used the argument "my body, my choice" and considered the embryo as their property or as part of their body. My religious beliefs were perhaps an influence, and are sure to resurface when speaking about assisted reproduction. As such, I have always felt that the embryo must be considered as its own "being" even though, as the Cour de Cassation has made clear time and again, that does not make it a "person".

Nevertheless, certain issues can arise to challenge the doctors who, motivated by their perfectly respectable commitment to "social gynaecology", perform pregnancy terminations where the woman's condition causes her distress, within the time limits that have also been the subject of much debate and which I will not go into at the present time. Among these issues, I will address just two: (1) requests for termination or embryo reduction in the event of twins; and (2) sex selection. 
Multiple pregnancies, especially higherorder ones, pose significant risks to the mother. Ovary stimulation and some in vitro fertilisations have confirmed this longknown fact. Embryo reduction is justified by these dangers, when well-informed patients request it. It is certainly acceptable for more than three embryos, and in some cases, for more than two. In order to avoid this situation, increasingly, two embryos at most are being transferred in in vitro fertilisation. But what happens in the case of twins, whether they are spontaneous or induced? What happens when the patient feels that the mere idea of having twins is unbearable, when she demands the reduction, regardless of the risks, and threatens to use the argument of termination "where the woman's condition causes her distress" if refused? Some doctors agree to it, and not so much because of the medical risks implied in having twins, which, as real as they are, may not justify the destruction of an embryo (and the psychological effects of such a decision). Rather, they agree mainly because "it is her right".

Even more delicate is the issue of sex selection. I will not go into detail about the various technical and chronological eventualities, which include preconception selection of the gametes, post-conception preimplantation selection by preimplantation genetic diagnosis, post-implantation prenatal selection by ultrasound scan, and one day perhaps by a simple blood test, or even postnatal, by direct or indirect infanticide. Sex selection, fortunately a minor issue in our country, remains a critical one in others, bringing into play philosophical concepts involving the status of children, social constraints resulting from the women's role in some societies, and lastly, ethical conflicts between the principle of respect of autonomy and that of non-discrimination. Again we wonder if this is a question of pragmatism or transgression. It is noteworthy that when sex selection was only considered possible through carefully planning the moment of fertilisation, or the mother's diet, the ethics of the choice itself were not an issue. While the technical effectiveness of such actions is doubtful, we must ask ourselves, does the ethical value of such an attitude depend on its result or its principle?

\subsection{From contraception to termination of pregnancy: the dilemma of "contragestion"}

The title of this section leads us to consider carefully a particular situation which we will come back to when speaking of in vitro fertilisation and which directly concerns the issue of the embryo's status.

We have covered the fact that the official doctrine of the Catholic Church reprobates both contraception and termination of pregnancy. I have already mentioned the reserved opinion that Charles Thibault and I held with regard to that doctrine. The problem is that scientific progress has created new debates in this area. Our experience with RU 486 has shown that it is an antiprogestin capable of terminating a pregnancy by pharmacological action. Nothing here distinguishes it from a vacuum-aspiration or dilation and curettage procedure, in terms of principle. However, in the future, a drug of the same type administered on the 25th day of the menstrual cycle could induce menses, which may contain, tangled with blood, a fertilised, unsuspected embryo. The problem is that, when such a drug is taken, there is a direct desire to not be pregnant, and furthermore, the woman who took it will never know what really happened inside her uterus. This is not science fiction. A similar situation occurs with a contraceptive coil, which does not impede the fertilisation of the egg, but instead the egg's implantation in the uterus lining. What implications does this have? Can women who today use the coil as a method of contraception be said to in fact have regular "discreet" abortions, perhaps on a monthly basis? It is as discreet as a spontaneous abortion; the difference is in the intention. Is the intention reprehensible, according to the fastidious critics? As you can see, and as the Vatican had perhaps sensed ahead of 
time, contraception and pregnancy termination can no longer be considered black and white. This is due to the use of biochemical or mechanical means liable to interfere with a possible pregnancy during the intermediate time interval between ovulation and a late period, ultimately achieving what E.E. Baulieu referred to as "contragestion". Does using a contraceptive coil, or perhaps one day a progestin better tolerated than the Pill, merely correspond to a practical attitude or does it constitute an ethically reprehensible transgression?

\section{ASSISTED REPRODUCTION}

The ethics of assisted reproduction are too involved to discuss here. I have often spoken about it with Charles Thibault, especially when we were working on a composite book $^{16}$ on the topic. I will simply underline a few major points.

\subsection{Donor Insemination}

Donor insemination had existed for a long time in deplorable technical and moral conditions, until Georges David founded CECOS, or centres for the study and storage of human eggs and sperm. These centres were designed with a clearly defined framework and collectively-established rules, ensuring that donors remained anonymous and were volunteers; they provided not so much a sperm bank as a generous donation from one fertile couple to another, infertile, couple. This remarkable enterprise has expanded and enjoyed continued success,

\footnotetext{
16 Aux débuts de la vie, des catholiques prennent position. Composite book. La découverte, 1990. Charles Thibault: L'Expérimentation sur les animaux et sur l'homme; Claude Sureau: La Procréation médicalement assistée; Michel Chartier: Diagnostic anténatal et médecine fotale; Georges David: Stérilité masculine et insémination artificielle; Jean Michaud: Science, religion et droit; Bernard Quelquejeu: Pour une véritable recherche éthique; Joseph Moingt: De nouvelles voies d'approche des problèmes génétiques en théologie morale; Paul Valadier: Cohérence et rigueur d'une pratique.
}

despite all sorts of obstacles and vehement criticism, among which the least offensive referred to it as "organised adultery" and an unacceptable threat to human dignity. The highest recognition of Georges David's initiative was probably given by the Catholic moralist René Simon, when he spoke of it in laudable terms as "ethical experimentation." In any case, in times where so much emphasis is placed on knowing one's roots and the importance of "genetic parentage", it is reassuring to see that France is still attached to the altruistic significance of a donor couple's actions. It effectively demonstrates the various meanings, each equally valid, of the term "parenthood".

\subsection{Egg donation}

Donations of eggs remain rare because they are forced to comply with what are clearly excessive sanitary precautions. A decree issued on 24 June 2004 should improve the situation.

In fact, the existing technical, philosophical and legal problems, for which we will have to find a solution, are rooted in cryopreservation. Technically speaking, freezing eggs has achieved less than excellent results and hopes that it will one day be efficient are lower than for the freezing of ovarian fragments. Theoretically speaking, the fragility of ovary cytoplasm is probably the cause for these failures. However, successful egg freezing is of utmost importance because it will avoid the necessity of embryo freezing, a major source of practical and ethical difficulties. For there to be significant improvement, experts will have to ensure that the procedure causes no harm to the embryo, which results from an oocyte that is first frozen, then thawed out. This means that an embryo will have to be created "for the purpose of research", which is strictly prohibited by both the Oviedo Convention ${ }^{17}$ and Article L-2151-2 ${ }^{18}$ of the

\footnotetext{
17 Article 18, Convention on Human Rights and Biomedicine, Oviedo, 04.04.97.
} 
Act dated 06.08.2004, yet permitted in the United Kingdom. Fear of transgression here, pragmatism across the Channel.

\subsection{IVF, ICSI}

Here again, I will not go into detail about IVF and ICSI (Intracytoplasmic sperm injection), essential advances for which we can particularly thank Charles Thibault for his experimental research, and Steptoe and Edwards for their human application. I will mention just three points:

- It is absolutely crucial that in-depth experimental research precede application in humans. This was the case for IVF, but not for ICSI.

- It is also absolutely essential to implement a means of monitoring of children born of these techniques. Georges David and, later, the French Academy of Medicine have been calling for follow-up of assisted reproduction techniques for over 10 years, after it was left out of the 1994 Act and stipulated in the Act of 06 August 2004 as the responsibility of the Agence de la Biomédecine.

- The question of surrogate mothers raises some very serious ethical issues, particularly that of "women exploiting women". While no entirely satisfactory solutions have been put forward yet, the United States and the United Kingdom have found some viable answers, either purely commercial (USA) or more humane (UK). Even more so than egg and sperm donation, surrogacy poses the question of whether the true definition of parentage and parenthood is genetic, biological or sociological.

\subsection{Embryo cryopreservation}

This is perhaps the crucial problem with assisted reproduction. There is certainly no doubt as to its usefulness, which is demon-

18 Art. L. 2151-2. "In vitro embryo production and cloning of human embryos for the purpose of research is prohibited." strated very practically. However, it introduces the idea of major transgression: that of temporarily suspending the development of a human being, of disrupting its biological clock, and the many practical consequences of this. The following are three such consequences:

- The ever-increasing number of surplus embryos and their future, along with the debate on what purpose they are to serve (i.e. Are they simply to be destroyed, or implanted, or used for research?) and thus their "use" in research may lead to consider the embryo and thus human life as a scientific instrument.

- With regard to the couples receiving the embryos, the unacceptable threat to confidentiality posed by the Act of 1994 and confirmed by the Act of 2004 .

- Above all, the unforgivably inhuman intentional error of these two Acts and their application: forbidding the posthumous transfer of a frozen embryo; and the embryo's outrageously absurd fate to be destroyed ("because it is better to be dead than to be an orphan"), or to be given to another couple because, it would seem, it is better to be without a mother and a father, than to simply have no father.

\subsection{General remarks}

The common thread in these three aspects of assisted reproduction is undoubtedly that it follows the same path first marked out by contraception, which aims to disassociate sexual intercourse from procreation. Again we find the problem of the letter and the Spirit - can we demand that intercourse and procreation be directly related each and every time? And therefore consider that any sexual act outside of the possibility to naturally conceive is immoral (this would include sterile couples' sexual intercourse, even sexual acts performed to extract sperm or to inseminate, sexual intercourse with pregnant women or women in menopause, or even intercourse during the infertile periods of a woman's cycle)? Or 
should we consider, from a highly religious/moral perspective, a couple's entire life together, and its consequences, whether natural or assisted, in terms of procreation?

Some may argue that reproductive cloning is the ultimate disassociation.

\section{CLONING AND TRANSGENESIS}

Why have I put these two seemingly distinct biological feats side by side? Although they are profoundly different, they are easily confused under the term "human genetic manipulation".

A common criticism of reproductive cloning is that "one being is created genetically identical to another being, whether alive or dead"19, 20. The clone, a "certified copy" of another being, is considered a serious threat to "human dignity" and therefore a "crime against the human species", punishable by law in France and which some people would like the international community to recognise as such.

It is difficult to encourage cloning and transgenesis, given our limited knowledge in the area, especially since the physical and socio-psychological consequences for the beings created are as yet unforeseeable and since experiments conducted thus far have revealed real risks. Nevertheless, we must admit that terms such as "certified copy", "threat to human dignity" and "crime" are exaggerations that reflect a mediocre understanding of biological and medical reality.

The specificity and uniqueness of a human being are not limited to nuclear genomic make-up alone. To say that they are, would be to forget the role of the mito-

\footnotetext{
19 Additional Protocol to the Oviedo Convention, 12.01.98. Article 1: "Any intervention seeking to create a human being genetically identical to another human being, whether living or dead, is prohibited."

${ }^{20}$ Act $2004-800$ of 06.08.04 relative to bioethics. Article 21: "Any intervention seeking the birth of a child genetically identical to another human being, whether living or deceased, is prohibited.'
}

chondrial genome, of epigenesis and, above all, in humans, the incredible independence of the brain and human behaviour with regard to genetic influence. It would be refuting human freedom and therefore human dignity; reducing Man to his genes, forgetting the experiments done on monozygous twins and reverting back to genetics as it was 30 years ago. Ironically, it would be denying the very specificity and uniqueness that are being defended; it would be limiting spirituality to a molecule of DNA. Paradoxically, it is by criticising mere biological cloning that people commit a fault against the human species, all the more so as it does not admit that the worst crime against the species was the ideological cloning which, sadly, destroyed so many human lives over the 20th century.

While somatic gene therapy has become more widely accepted, many still object to germ line therapy, involving the zygote or the gametes, supposedly in order to protect the genome, which, curiously, is symbolised as the "heritage of humanity". This is tantamount to accepting that a congenital abnormality be corrected in an individual, but at the same time denying that the same abnormality be prevented in that individual's offspring. That is precisely what Article $13^{21}$ of the Oviedo Convention implies, while, thankfully, Article $16.4^{22}$ of the French Civil Code allows for the possibility of research to prevent the abnormality in offspring also.

It is interesting to note that, as a result of these Articles, each full of good intentions, reproductive cloning combined with transgenesis should not be considered a criminal act since the genetic make-up of the being

\footnotetext{
21 "An intervention seeking to modify the human genome may only be undertaken for preventive, diagnostic or therapeutic purposes and only if its aim is not to introduce any modification in the genome of any descendants."

22 "Without prejudice to research for the prevention and treatment of genetic diseases, genetic traits may not be manipulated in any way whatsoever with a view to modifying the genetic make-up of an individual's descendants."
} 
born of the two processes will be "original", and not identical to any other being, whether alive or dead.

As far as cloning by nuclear transfer "for the purpose of research" is concerned, aside from its potential therapeutic application, which we will discuss later, and a better understanding of the first stages of development, I would like to underline two points:

- The status of the embryoid body is ambiguous: is it an embryo because it could become a person, even though it was created for another purpose? Or can it not be referred to as such because it has not been fertilised? What would an embryoid body obtained by parthenogenesis be considered?

- Cloning research could have practical benefits if it leads to the realisation of "artificial meiosis". This type of meiosis would provide a solution for currently-untreatable sterility by ensuring the genetic unforeseeability inherent to fertilisation and would therefore make reproductive cloning useless. The transgression in this case would lead to a pragmatic advance.

\section{RESEARCH ON STEM CELLS AND HUMAN CELL LINES}

On 7 May 2002, the French Academy of Science and Academy of Medicine came to an agreement on the need for research on stem cells and human cell lines. This research was to be conducted first in animals, then in humans in order to compare the efficacy and innocuousness of cell lines derived from stems cells of various origins: adult individuals (e.g. blood, bone marrow, tissue), foetuses (e.g. tissue from aborted foetuses, umbilical cord blood) and embryos, including surplus IVF nuclear transfer embryos, and even parthenogenetic embryos.

Again and for the last time, Charles Thibault and I were in agreement on this point, where transgression seemed justified by the practical potential interest of therapeutic applications. In the Spring of 2002, we met at the Ministry of Research with Ms Le Douarin, Ms Le Mintier and Ms FagotLargeault to give a favourable opinion on importing cell lines from surplus Australian embryos. Some time later, the courts and the government came to a decision, and, with the Act of 6 August 2004, finally accepted the possibility of such research, at least for an experimental period of five years.

Unfortunately, the same Act did not authorise research on cell lines by nuclear transfer. We will therefore have to await the outcome of research being done in the United Kingdom and elsewhere. If this research does not find any definite applications, the French authorities will be justified in having insisted on caution with this type of research, and the awful transgression it represented. On the contrary, if the research leads to clinically proven progress, it will push the authorities to reflect on the practical aspects of such research and to consider the public interest in accepting the possibility of treatments that will be demanded by patients and their families, and this despite their ideological and philosophical reservations.

\section{EMBRYO RESEARCH AND MEDICINE}

Embryo research is admittedly shocking for many people. It nevertheless seems necessary and was in fact authorised by the Act of 6 August 2004. The reasons for its necessity have been mentioned several times throughout this article: to elucidate the mechanisms responsible for congenital malformations, and, if possible, to prevent them and to thus avoid so-called "medical" terminations of pregnancy; to improve the still-imperfect results of assisted reproduction; to do away with the constraint of freezing embryos via oocyte cryopreservation; to help couples who today still suffer from untreatable infertility, without the development of reproductive cloning; and, of course, to use cell lines from this research 
for numerous medical applications whose indications we are just beginning to discover.

That said, we must not delude ourselves. Unlike medical research in general, embryo research implies the destruction of the beings it relies on: embryos that have been identified as abnormal from the first stages of their development, which are not transferred and whose death is therefore unavoidable. However, it also makes use of normal embryos, with the approval of the parents, who have abandoned their "parental plans" for whatever reason.

It is important to realise that this is a major transgression, the justification for which lies in the abovementioned reasons. In fact, the embryos, alive but with no future, are sacrificed in order to provide better conditions for future, hypothetical embryos. There is an obvious comparison to be made here with ectopic embryos, mentioned earlier in the presentation. Just as in an ectopic pregnancy, one being is today sacrificed for a future, expected being.

We can only further regret that the Act of 6 August 2004 did not authorise research on zygotes by nuclear transfer, whose ontological "value" appears less compared to that of surplus embryos. The situation is all the more bizarre since France has prohibited this type of nuclear transfer within its borders, but at the UN, has sided with countries like the United Kingdom and Belgium, who are demanding the approval of therapeutic cloning.

\section{CONCLUSION AND SUMMARY}

Jean Hamburger wrote "The scientific data available to us today cannot obey morals which were born without knowledge of them". This is a remarkably meaningful sentence still today, for all members of humanity, whatever their role or activity in society - for patients, whether beneficiaries or active participants in medical procedures with heavy implications; for researchers and practitioners; but also for future generations who will live in a world that our decisions will have made better, or worse, depending on your point of view.

This uncertainty is a source of worry for us all, believers and unbelievers alike. But it is particularly significant for the former, among whom Catholics, who are faced with the unquestionable conflict between official moral doctrine, rather than dogma, and scientific progress and its potential applications in relieving human suffering. It is a conflict that involves "doing good" and "doing one's duty", mentioned at the beginning of the article. In a number of situations, it requires referring back to Jesus' teachings on compassion and charity, and risking exposing oneself to criticisms of giving in to pragmatism, and preferring secularism to blind obedience of the Church.

It also implies, in our diverse society, accepting pluralism and refusing to take advantage of the prevailing situation to impose one's convictions on others who do not share them. In 1967, with respect to the Neuwirth Act, Reverend Riquet insisted, "Christians must not... use the Law to impose their personal point of view". More recently, Anne Fagot-Largeault wrote, "to accept pluralism does not necessarily lead to moral nihilism", a telling comment that, incidentally, brings up the issue of the "universality" and "durability" of ethical rules.

Medical practitioners are most often confronted with these issues; their experience with finding "humane solutions to human problems", to paraphrase Chancellor Daguessau's statement about law, can serve not as a model, but an example. As we have seen throughout this article, the generalised destruction of ectopic and anencephalic embryos, the legitimacy of pregnancy termination in order to prevent an unbearable life and death for children with epidermolysis bullosa, and so many other "major transgressions" are considered perfectly acceptable by practitioners. However, they are aware that they may be on the slippery slope that ultimately leads to the 
loathsome excesses of facility, selfishness, convenience and utilitarianism. Between compassion for others, helping those who are in need and protecting more fragile human beings, where does embryo research and the use of some cell lines, which necessarily label such humans as "secondrate," stand? Referring to the rule of Law is useless in this context, as it refrains from classifying the unborn according to the standard categories of persons and things, supposedly a vestige of Roman Law.

Biomedical ethics, far from being a fallacious assimilation "of Ethics and Law" [de Ethique au Droit], to use the title of the 1998 report of the Conseil d'État ${ }^{23}$, or the somewhat appalling title commonly used for the laws of 1994 ("laws on bioethics"), repeated in part in those of 2004 (law "relative" to bioethics), are above all the responsibility of individual conscience, whether patient or practitioner. As Pastor Michel Bertrand said, "Too much law puts the conscience to sleep", a statement that applies to agnostics and believers.

It is in the individual conscience that the inevitable transgressions of "moral law" find their place, where they force the individual to "accept transgressions in the name of responsibility, without upholding the transgression in and of itself", as Marc Grassin once put it well. This is the path, long marked out by Charles Thibault, towards the fairer, more humane Society he dreamt of.

23 Translator's note: Specialist independent advisory body to the government on proposed legislation, with a watching brief over all public administrative actions. 